\title{
Synchrotron-based micro-analyses of artistic materials at ID21, ESRF
}

Marine Cotte $^{1}$, Letizia Monico ${ }^{2}$, Koen Janssens ${ }^{3}$, Wout De Nolf ${ }^{1}$, Murielle Salomé ${ }^{1}$, Juliette Langlois ${ }^{4}$

${ }^{1}$ Id21, Esrf, Grenoble, France, ${ }^{2}$ Department of Chemistry, Biology and Biotechnologies/ SMAArt Centre and CNR-ISTM, University of Perugia, Perugia, Italy, ${ }^{3} 3$ Department of Chemistry, AXES Research Group, University of Antwerp, Antwerp, Belgium, ${ }^{4}$ Centre de Recherche et de Restauration des Musées de France (C2RMF), Paris, France E-mail: cotte@esrf.fr

The ID21 beamline is an analytical platform at the European Synchrotron Radiation Facility offering four end-stations: three in focussed beam scanning mode, exploiting micro X-ray fluorescence ( $\mu$ XRF), micro X-ray absorption spectroscopy ( $\mu$ XAS), micro X-ray diffraction ( $\mu$ XRD) and infrared micro-spectroscopy ( $\mu$ FTIR), and one in unfocussed full-field mode dedicated to $X$-ray absorption spectroscopy (FF-XAS). This beamline has an important activity in the field of cultural heritage [1]. Instruments can be efficiently used to gather information about the way works of art were manufactured (choice of ingredients, being natural or synthetic, firing conditions, etc). Besides, many analyses are dedicated to artwork conservation and preservation through a better understanding of the composition of degradation products formed with time and through the assessment of effects of external parameters (humidity, light, pollutants, etc) and internal parameters (material initial composition) on degradation processes.

The X-ray energy range (2.0-9.1 keV) gives access not only to low $Z$ elements such as $S$ (present in many sulfide pigments), but also to most of the $3 \mathrm{~d}$ transition metals (in particular $\mathrm{Mn}, \mathrm{Fe}, \mathrm{Co}, \mathrm{Cu}$, responsible for the color of many pigments). Heavier metals such as $\mathrm{Sn}, \mathrm{Sb}, \mathrm{Pb}$ can also be analyzed, through their $\mathrm{L}$ or $\mathrm{M}$ edges. Elements can be identified and localized with a submicrometric resolution thanks to $\mu$ XRF. Their chemical and structural environment can then be further determined using spectroscopy and diffraction techniques.

The $\mu$ FTIR operates in the mid-infrared domain $(4000-700 \mathrm{~cm}-1)$ and is a very powerful instrument for the characterization of molecular groups, in particular in organic materials. Chemical maps can be obtained with a lateral resolution of a few microns.

The complementarity of the different instruments permits to study almost all types of materials, from hard matter (pigments, glasses, ceramics) to soft matter (papyri, plastics) and also mixtures of these different materials (e.g. paints [2], modelling materials [3], photographs). Analyses are usually carried out on tiny fragments from historical artworks (e.g. paint fragments from Van Gogh's paintings [2]; modelling material fragments from Rodin's sculptures [3]) which can be completed by the analysis of model samples, mimicking historical ones and possibly artificially aged. Different recent applications will be presented.

[1] Cotte, M., Pouyet, E., Salome, M., Rivard, C. De Nolf, W., Castillo-Michel, H., Fabris, T., Monico, L., Janssens, K., Wang, T., Sciau, P., Verger, L., Cormier, L., Dargaud, O., Brun, E., Bugnazet, D., Fayard, B., Hesse, B., Pradas del Real, A. E., Veronesi, G., Langlois, J., Balcar, N., Vandenberghe, Y., Sole, V. A., Kieffer, J., Barrett, R., Cohen, C., Cornu, C., Baker, R., Gagliardini, E., Papillon E. \& Susini, J. (2017). J. Anal. Atom. Spectr..

[2] Monico, L., Janssens, K., Hendriks, E., Vanmeert, F., Van der Snickt, G., Cotte, M., Falkenberg, G., Brunetti B. G., \& Miliani, C., (2015). Angew. Chem. 127, 14129-14133.

[3] Langlois, J., Mary, G., Bluzat, H., Cascio, A., Balcar, N., Vandenberghe Y., \& Cotte, M. (2016). Stud. Cons.

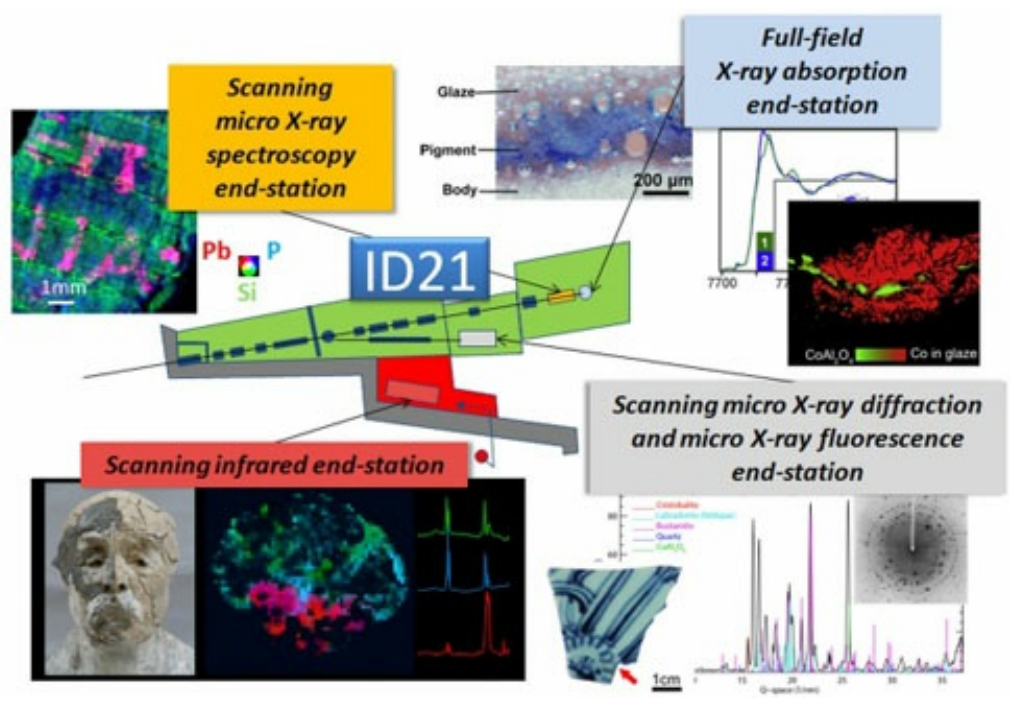

Keywords: Paintings, ceramics, conservation 